\title{
Marketing accountability and marketing automation: evidence from Portugal
}

\author{
Marketing \\ accountability \\ and \\ automation
}

Susana C. Silva

Catolica Porto Business School and CEGE, Universidade Catolica Portuguesa, Porto, Portugal

Leonardo Corbo

University of Bologna, Bologna, Italy and

CEGE, Catolica Porto Business School, Universidade Catolica Portuguesa, Porto, Portugal, and

Božidar Vlačić and Mariana Fernandes

Catolica Porto Business School and CEGE, Universidade Catolica Portuguesa, Porto, Portugal

\begin{abstract}
Purpose - The present study seeks to outline the role of marketing automation (MA) in measuring the return on marketing activities and the challenges associated with reaching accountability in marketing.

Design/methodology/approach - To investigate the objective of the study, the authors adopted a qualitative approach, conducting an exploratory study among ten key informants located in Portugal.

Findings - Based on the results of the qualitative analysis, a conceptual framework is proposed, which includes both strategic- and operational-level factors with the goal of creating a value-based agenda. In this agenda, executives such as the Chief Marketing Officer emerge as value creators, fostering business scalability, and further arguments are provided to justify budget allocation to MA activities.

Originality/value - Through careful research of the elements that characterize the phenomenon under study, the present paper ultimately contributes to a better understanding of MA and accountability within the current business paradigm.
\end{abstract}

Keywords Accountability, Automation, Marketer, Marketing, Performance measurement

Paper type Research paper

\section{Introduction}

In a world governed by rapid technological changes and volatility, the creation of value and business survival is dependent on effective data gathering and analysis. In such an uncertain environment, Vrontis et al. (2012, p. 432) put forward the concept of strategic reflexivity, indicating that companies "should set up knowledge-based mechanisms that reflexively react to environmental changes." In order to cope with the evolving environment, advancements in information technology (IT) have brought an increasing amount of data available to companies (Kübler et al., 2017). In particular, within the scope of marketing initiatives, such improvements gave birth to marketing automation (MA) (Bucklin et al., 1998; Davenport and

(C) Susana C. Silva, Leonardo Corbo, Božidar Vlačić and Mariana Fernandes. Published by Emerald Publishing Limited. This article is published under the Creative Commons Attribution (CC BY 4.0) licence. Anyone may reproduce, distribute, translate and create derivative works of this article (for both commercial and non-commercial purposes), subject to full attribution to the original publication and authors. The full terms of this licence may be seen at http://creativecommons.org/licences/by/4.0/legalcode

The authors would like to thank CEGE - Research Centre in Management and Economics, funded by the Multiannual Funding Programme of R\&D Centres of FCT - Fundação para a Ciência e a Tecnologia, under the project UIDB/00731/2020, for its support.

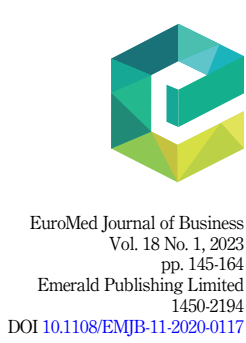

Received 3 November 2020 Revised 17 March 2021 13 April 2021

Accepted 20 April 2021 
EMJB 18,1

Philips, 2016). Yet, as the amount of data available evolves, it becomes harder for marketers to discern what information can be leveraged to achieve favorable business outcomes. Therefore, it has become even more important to employ MA platforms that administer the essential information and provide the required accuracy in the relevant areas (Kauffman et al., 2018; Mero et al., 2020).

A large body of literature has acknowledged that several challenges have resulted in immense pressure for marketers to justify their expenditures and translate them into likely financial outcomes. These include growing costs and competition (Mishra, 2011), managers' frustration over the gap between the promise and practice of effective measurement (Hanssens and Pauwels, 2016) and the increased focus on data-driven marketing (Arslanagic-Kalajdzic and Zabkar, 2015; Grandhi et al., 2020). As such, marketers face the most complex undertaking, namely being recognized as a creator of value inside the company (Ulaga, 2003; Patterson, 2014). Building on recent contributions highlighting the need to explore how marketing accountability is achieved (e.g. Arslanagic-Kalajdzic and Zabkar, 2015), in this paper, we put forward the idea that the automation of marketing activities can help marketers being recognized as essential value creators and ultimately improve firms' returns on marketing.

Despite the novelty of this problem, there is a clear consensus on four major aspects. First, accountability in marketing is no longer optional (Morgan et al., 2002; O'Sullivan and Abela, 2007; Stewart, 2009) given the increased pressure upon marketers to display results that justify further budget allocation (Mishra, 2011) and legitimize their role inside the company as essential value creators (Davenport and Philips, 2016). Second, marketers are continuously facing difficulties in finding the right system of metrics to accurately measure the financial performance outcome of their activities (e.g. Copulsky et al., 2016). Third, within the new marketing paradigm, ruled by data explosion and tremendous advancements in automated systems, marketers are forced to acknowledge this shift by adapting processes, skills, roles and strategies toward data-driven actions if they wish to stay ahead of the competition and sustain profitable growth (Kumar and Sharma, 2017; Huang and Rust, 2021). Lastly, while still in the early days of its implementation, MA is well on its way to becoming the answer to a field that is consistently more quantitative, connected to measurable business results and dependent on decision-making based on data and analytics (Davenport and Philips, 2016; Grossberg, 2016; Stanton and Stanton, 2016).

Taking into consideration that companies implementing advanced technological systems have the upper hand on tactical advantages (Järvinen and Taiminen, 2016; Vrontis et al., 2016), we aim at understanding and describing how businesses can leverage the successful implementation of MA software in order to enhance the return on their marketing activities. We also aim to explore how this implementation can be coordinated with other strategies to develop a framework that explicitly incorporates accountability into marketing activities undertaken by managers and their teams. While previous research has addressed the topics of accountability in marketing and MA (Biegel, 2009; Stewart, 2009), less is known about the link between MA and marketing accountability. This gap provides the opportunity to address the following question: How does the implementation of marketing automation software impact the return on marketing investment?

We explore this research question by adopting a qualitative approach. Using purposeful sampling, we relied on a sample of ten cases of companies located in Portugal. Managers involved in marketing activities were interviewed, while secondary sources were used to triangulate results. Overall, our findings indicate that MA can be a valuable ally for marketers seeking to overcome the challenges associated with reaching accountability in marketing and, as a result, improve the return on marketing activities.

A review of the existing literature on MA and accountability in marketing is developed in the following section, accompanied by a proposed conceptual model. Next, the methodology and the development of this investigation are described in detail. Then, the study results are 
presented, followed by a discussion of the main contributions and suggestions for further research paths.

\section{Literature review}

\subsection{Marketing and information technology}

Marketing is "rapidly becoming one of the most technology-dependent functions in business" (Brinker and McLellan, 2014, p. 82). In fact, it operates within a complex digital ecosystem (Makrides et al., 2020) in which firms try to comprehend and reach their target customers and markets in a rapid, systematic and cost-efficient fashion (Vrontis et al., 2017). Furthermore, analytic tools provide decision-makers with unparalleled information on customers, finances, operations, suppliers and the market, presenting themselves as a compelling source of competitive advantage for marketers (Gillon et al., 2014). Hence, instead of differentiating themselves solely on their products or services, companies are now also forced to compete on analytics (Davenport, 2014; Joshi and Giménez, 2014).

The way that companies and marketers are able to deal with the existent data can be considered as a leverage source of competitive advantage, especially within the digital paradigm (Hajdas et al., 2020; Kumar et al., 2020). Hence, firms leveraging marketing analytics and IT to their advantage are able to determine consumers' needs, predict how much they are willing to pay, which channels they prefer and at what time (Siegel, 2016; Hajdas et al., 2020; Silva et al., 2020). Overall, the influx of data is growing, and, consequently, so are the tools that allow gathering insights based on analytics (Sarmaniotis et al., 2013). Thus, businesses need to invest in technology, and marketers must review their relationship with IT regularly if they wish to survive and sustain a competitive advantage in the long run (Kumar and Sharma, 2017).

\subsection{Marketing automation}

Within the current business landscape, the amount of marketing decisions involving complex variables and large quantities of data is too much for marketers to handle (Davenport and Philips, 2016; Huang and Rust, 2021), making the automation of marketing processes a very appealing solution. Thanks to services that track, score and implement digital marketing and communication services, efficiency is now almost certain (Kumar et al., 2020), and marketers can see several benefits realized in terms of effectiveness (Lois et al., 2020). In order to achieve these benefits, "marketers are looking to refine internal processes in order to gain better control, visibility and overall efficiency in marketing operations" (Biegel, 2009, p. 202). By doing so, they bring together marketing and data science to help users define their target audience, optimize conversion and generate more revenue (Grossberg, 2016; Festa et al., 2020). Consequently, firms can manage costs better, enrich customer journey, shorten marketing cycle periods and improve targeting to support the new wave of hyper-personalized marketing (Silva et al., 2021).

MA is nowadays employed mostly for personalized pricing, communication and buyer journey, harnessing the reputation of a solution that can bring considerable revenue and results (Duarte and Silva, 2020). These marketing technologies combine software, networks and hardware that allow the inputs, processing and outputs of marketing and business information and content. MA entails using software to automate marketing activities such as email marketing, social media posting, ad campaign production, lead generation, marketing analytics and even relationship management, among others. The technology of MA makes these tasks more efficient and personalized. In this sense, MA systematizes processes, thus organizing and measuring marketing tasks effectiveness as well as improving control measures. According to Redding (2015), MA derives from software that grew on the basis of email systems that provide automated campaigns triggered by customers' behavior,
Marketing
accountability
and
automation

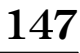


EMJB 18,1

addressing specific customer segments. Accordingly, MA can lead to an increased return on marketing investment as it makes processes that would otherwise be performed manually significantly more efficient. Building on this idea, Järvinen and Taiminen (2016) argue that MA tools deliver more effective content marketing strategies and improve lead follow-up practices. It also provides the glue that aligns sales and marketing and provides more customer-focused business (Redding, 2015).

At its core, MA hyper-personalizes marketing activities (Heimbach, 2015), tailoring the entire marketing mix to each specific customer through the use of search data, social content and email campaigns to track individual visitors, what they have seen and what they are keen to see next. Hence, MA provides marketers with access to a much broader understanding of each prospect (Grossberg, 2016), enabling the development of customized content, personalized offers and ultimately reducing uncertainty (technological and market-driven) (Mero et al., 2020).

The main features of an MA platform can be summarized as lead management, campaign management, email marketing, progressive profiling and dynamic content. While these represent the main elements of MA, the aforementioned features fall short of fully describing the large cluster of possibilities MA offers-content, structure or attribute customization of an offer based on triggers like time, date, IP address, device or browser, email personalization, channel, landing page and website customization, personal information gathering, like keyword search, buying patterns and real-time browsing behavior all represent very real and useful tools provided by MA (Biegel, 2009). The benefits of MA seem to be indisputable and compelling, resulting in a more effective marketing strategy (Sarmaniotis et al., 2013) and a higher return on marketing investment (ROMI) (Biegel, 2009).

\subsection{Accountability in marketing and the role of marketing automation}

Marketing performance measurement has been a significant source of concern both for researchers and practitioners alike for many years (Lamberti and Noci, 2010). The challenge of measuring the ROMIs is also known as marketing accountability, which is "the responsibility for the systematic management of marketing resources and processes to achieve measurable gains in ROMI and increased marketing efficiency while maintaining quality and increasing the value of the corporation." (American Marketing Association, 2005, p. 1). The need for better accountability in marketing is further exacerbated by the incremental growth in costs and competition that propels marketing departments to justify their expenditures (Mishra, 2011). In fact, there is universal agreement among researchers and practitioners regarding the absence of common guidelines for measurement of the impact that marketing activities have on firm performance (Järvinen and Krjaluoto, 2014; Patterson, 2014; Copulsky et al., 2016; Hanssens and Pauwels, 2016). MA seems to be the suitable technology that attempts to tap the need for control derived from the market uncertainty and the existence of an array of more sophisticated techniques to turn firms' actions more accountable and controllable (Read et al., 2009; Mero et al., 2020).

In light of the need for better marketing accountability, MA stands apart as a solution that can generate considerable revenue and results (Kauffman et al., 2018) and become a true ally for marketers who seek more accurate performance management tools. MA "provides a level of efficiency and timeliness that simply cannot be matched by human intervention, no matter how responsive (...) marketing or client-facing teams are" (Wood, 2015, p. 253). As a consequence, marketers can attribute with precision each accomplishment to the respective campaign or conversion point. MA can also incorporate data from several channels into a single platform, turning the assessment of performance and effectiveness of each channel into a seamless process (Kauffman et al., 2018). Essentially, what this means for marketers is unprecedented access to measurable results at any point in a campaign, providing timely 
insights on the behavior of potential customers along their journey, which in turn allows for adjustments and fine-tuning in real-time (Järvinen and Taiminen, 2016), with eventual realignments in strategic decisions. These results have been reported in different contexts, including the drug industry (Alsaad et al., 2018), wine tourism (Festa et al., 2020) and financial services (Wright et al., 2008), but there is still a scarcity of empirical research.

In summary, research has already made clear that marketers interested in accountability for their actions are the ones that normally achieve better ROMI and higher performance levels. Nevertheless, the literature review revealed a scarcity of studies exploring and successfully translating the correlation between the performance measurement of marketing activities and the implementation of MA software. As such, further research is necessary at this level.

\section{Methodology}

\subsection{Research strategy}

To address our research question and provide more insights on marketing accountability in the era of automation, we employed a qualitative approach (Gehman et al., 2018). This approach was developed taking as groundwork the notion of putting MA into practice. By doing this, companies are able to improve the alignment between strategic and operational activities (Malshe et al., 2017; Bornet et al., 2021), leading to better integration within the organization and ultimately higher value creation (see Figure 1).

For testing the proposed conceptual relationships among the MA, strategic-operational marketing and marketing accountability, a three-staged qualitative research design is developed by the authors, as suggested by Gioia et al. (2013). The research stages are unitizing, categorizing and aggregation (see section 3.3 and Table 2). In the unitizing stage, researchers identify key terms and thought units that can range from a single term to a whole sentence. Next, in the categorizing stage, the components of the MA are explored and categorized. In the aggregation stage, the identified components of marketing accountability are positioned and shown on the conceptual model (Figure 2).

In the study, the participants of semi-structured interviews are purposefully selected (Yin, 2003) from Portuguese company employees. To be eligible for the study, the interviewees had to meet three main criteria (Eisenhardt, 1989): (1) occupy a position with marketing responsibilities within their organization (i.e. chief executive officer (CEO), chief marketing officer (CMO), head of growth or any other role that directly correlated with managing marketing activities inside a firm); (2) actively use MA software to carry out or otherwise facilitate the implementation of marketing activities; (3) actively measure the performance of marketing activities through data and analytics. The particular interest in conducting a study among Portuguese marketers lies in the fact that according to the Global Skill Index (Coursera, 2019), Portugal is considered one of the competitive economies in business, technology and data science.

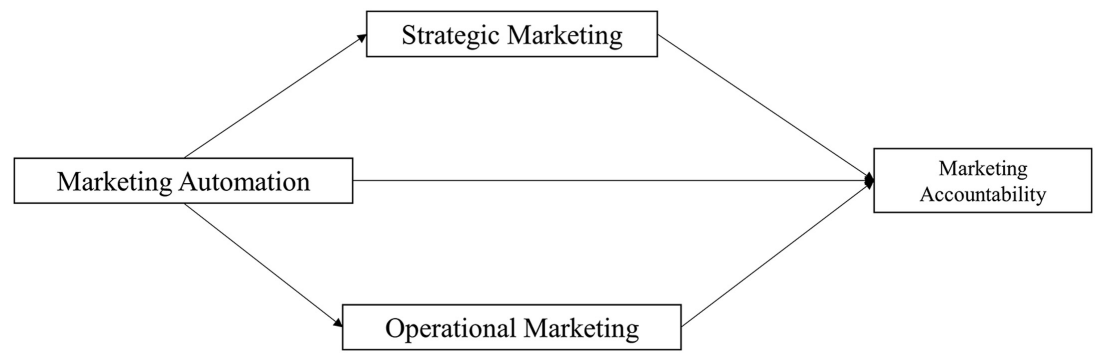

Figure 1.

The identified components of marketing accountability 


\section{EMJB}

18,1

150

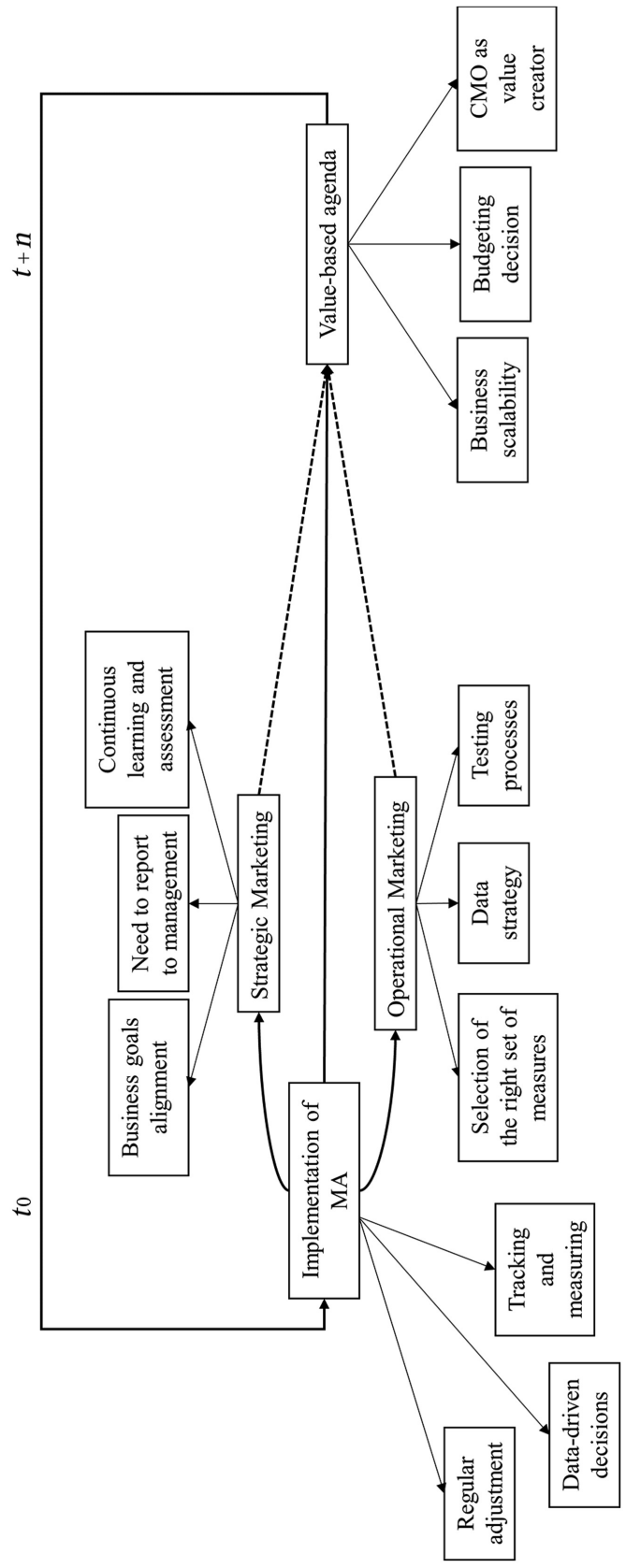

Figure 2. accountability in marketing 


\subsection{Administration and implementation of the semi-structured interviews}

A qualitative analysis through semi-structured in-depth interviews with marketing managers of ten companies was performed during a period of six months. Accordingly, indepth interviews arise as the best form of data collection for this particular study (Minichiello et al., 1990). This approach allows the gathering of relevant information and a broader understanding of marketing accountability, the biggest challenges in reaching it, and the ultimate impact of MA on measuring marketing activity performance (see Vrontis et al., 2012). In addition to interview data, secondary data in the form of direct observation and reports, websites and official databases were also gathered. Similar to other studies where the information involved is of strategic importance (e.g. Santoro et al., 2019), managers agreed to be interviewed on a no-name basis with granted confidentiality and anonymity. While, in principle, anonymous case studies might present limitations, in our case, they allowed us to collect finer-grained and otherwise difficult to obtain information. While preserving the identity of the companies, we were allowed to share some descriptive information on the profile of the interviewees (see Table 1).

All interviews lasted between 30 and 90 minutes and were recorded with the permission of the participants and later transcribed by the researchers within 24 hours. Interviewees were questioned about the strategic interest of the use of operational tools in their quest for better marketing accountability. Hence, questions covered topics such as the need for accountability, how to implement it and the effective use of MA. The interview guide and the related questions are available in Appendix.

\subsection{Analysis of the interview data}

Upon the data collection, an international team of researchers accumulated the transcripts and created a unified dataset. Following the abductive approach (Dubois and Gadde, 2014; Mero et al., 2020) and with the assistance of the NVivo 12 software, researchers interpreted the

\begin{tabular}{|c|c|c|c|c|c|}
\hline Firm & Industry & $\begin{array}{c}\text { Industry } \\
\text { classification } \\
\text { (CNAE, 2009) }\end{array}$ & $\begin{array}{l}\text { Number of } \\
\text { employees }\end{array}$ & $\begin{array}{l}\text { Interviewee } \\
\text { role }\end{array}$ & Gender \\
\hline 1 & $\begin{array}{l}\text { Computer consultancy and } \\
\text { programming activities }\end{array}$ & 5829 & 10 & $\begin{array}{l}\text { Marketing } \\
\text { Manager }\end{array}$ & Female \\
\hline 2 & Food retailing web platform & 6312 & 257 & $\begin{array}{l}\text { Head of } \\
\text { E-commerce }\end{array}$ & Male \\
\hline 3 & Publishing house and book retail & 8299 & 460 & $\mathrm{CEO}$ & Male \\
\hline 4 & $\begin{array}{l}\text { Computer consultancy activities } \\
\text { and programming activities }\end{array}$ & 5829 & 18 & Head of Growth & Male \\
\hline 5 & $\begin{array}{l}\text { Organization of conventions and } \\
\text { trade shows }\end{array}$ & 8230 & 44 & Head of Growth & Male \\
\hline 6 & $\begin{array}{l}\text { Data processing, hosting, and } \\
\text { related activities }\end{array}$ & 6311 & 16 & Head of Growth & Male \\
\hline 7 & $\begin{array}{l}\text { Computer consultancy activities } \\
\text { and programming activities }\end{array}$ & 6201 & 34 & Head of Growth & Male \\
\hline 8 & $\begin{array}{l}\text { Production, transformation, } \\
\text { distribution, commercialization, } \\
\text { and promotion of wines }\end{array}$ & 1102 & 22 & $\begin{array}{l}\text { Chief } \\
\text { Marketing } \\
\text { Officer }\end{array}$ & Female \\
\hline 9 & $\begin{array}{l}\text { Computer consultancy and } \\
\text { programming activities }\end{array}$ & 5829 & 5 & $\begin{array}{l}\text { Chief } \\
\text { Marketing } \\
\text { Officer }\end{array}$ & Male \\
\hline 10 & $\begin{array}{l}\text { Wholesale of clothing and } \\
\text { footwear }\end{array}$ & 4642 & 1142 & $\begin{array}{l}\text { Clients and } \\
\text { Digital Director }\end{array}$ & Male \\
\hline
\end{tabular}

\section{Marketing accountability and automation}


EMJB
18,1

152

First phase (unitizing)
Statements regarding the importance of marketers'
alignment with business goals
Statements indicating marketers necessity to report to
senior management

Statements showing the importance of continuous learning

and assessments

Testimonials revealing the importance of appropriate metrics selection

Statements indicating the necessity for robust data strategy

Expressions regarding sound testing processes and stepwise incorporation of new processes

Thought units reflecting the importance of data-driven marketing activities

Statements regarding the necessity for continuous adjustment and overall importance of state-of-art

technology such as automation

Expressions referring to the capabilities of tracking and measuring activities in line with the implementation of MA Statements indicating the importance of business scalability and marketers capability to reach and exceeds the business objectives

Thought units indicating the importance of and approaches toward budgeting decisions

Table 2.

Data structure

Statements portraying the necessity of recognizing marketers as value creators decisions and overall relevance of data in contemporary
Second phase

(categorizing)

Business goals

alignment

Need to report to

management

Continuous learning

and assessment

Selection of the right set Operational

of measures

Data strategy

Testing processes

Data-driven decisions

Implementation of MA

Regular adjustment

Tracking and

measuring

Business scalability Value-based agenda

Budgeting decisions

$\mathrm{CMO}$ as a value creator

Third phase

(aggregation)

Strategic marketing

marketing

data in line with theoretical foundations while remaining open-minded to the constructs emerging through the analysis. The abductive approach enables enhancing a priori theoretical constructs and enables alignment with empirical findings (Fletcher $e t$ al., 2018; Vlačić et al., 2020). Thus, the codes were set in place to identify and differentiate patterns, both based on the previous literature review and for new subjects that arose, and comments were placed next to each key section of the interviews. The coding procedure was performed in line with Gioia's three-stage grounding approach (Gioia et al., 2013). This approach consists of three consecutive phases. In the first phase, researchers perform unitizing the identified thought units (i.e. words, phrases, sentences or several sentences). Once the thought units are identified and grouped to outline the ones relevant for the research objectives, researchers proceed to the second stage, known as categorizing. In the second phase, thought units are categorized into preliminary concepts and assigned descriptive labels (e.g. business goals alignment, need to report to management, continuous learning, and assessment, selection of the right set of measures, data strategy, testing processes, data-driven decisions, regular adjustment, tracking and measuring, business scalability, budgeting decisions, $\mathrm{CMO}$ as value creator). Lastly, in the third phase, called aggregation, thoughts and sub-constructs identified in the first two phases are comprehended into aggregate dimensions. The overview of this three-phase procedure is outlined in Table 2.

Overall, the identified dimensions and interplay between theoretical background and empirically collected data enabled developing a unified framework presented in Figure 2. The data analysis process consists of reading and absorbing information, coding, counting the frequency of each code, reducing the amount of data, finding correlations with the theoretical 
model, and then repeating the process until it reached the point of theoretical saturation (Sinkovics and Alfoldi, 2012). In sum, the adoption of this methodological approach allows extracting the basic blocks that can make up a more comprehensive and finer-tuned framework.

\section{Findings}

4.1 The demand for accountability in marketing through MA implementation

Our findings reveal that firms consider it essential that marketing managers and their teams are held accountable for the activities undertaken and the direct results these activities have on profitability and sustainable competitive advantage. These activities are relevant at both the operational and the strategic levels. Several factors arose as drivers of this increasing demand for accountability. For example, manager 3 mentioned: "We bought the oldest bookshop in the world in 2006, and since then we realize that we had no alternative than using accountability as much as possible. Numbers allow us to free up people for more human-based tasks. Step-by-step, we made each client accountable and traced their journey with us. It took us some 5 five years to be able to change our systems. (.. .) Now we can say we have a true level of accountability." Additionally, manager 4 highlighted that the role of a marketer is "more and more (...) oriented towards metrics and measuring practically everything," which reinforces the notion that marketing activities are increasingly dependent on analytics, which includes tracking and measuring, and data-driven decisions, as numbers are continuously compared to the past. It also elicits the idea that continuous learning and assessing should be stimulated, and regular adjustment should be kept in mind.

The ability to measure the outcome of marketing activities was further emphasized through elements inherent to the new business paradigm, in which business goals are aligned with the new automation paradigm at a strategic level. Manager 1 addressed the issue of accountability as a byproduct of growing competition, stating that "the digital market is increasingly more competitive, and there is a need almost to measure everything by the millimeter so you can be head to head with your competitors, and above them if possible." In addition to this factor, the call for accountability in marketing also arises due to the need marketers to report to the management and justify further budget allocation through the results of previous activities, as noted by manager 5: "There is a lot of accountability surrounding companies because there is a pressure to scale, to scale very fast, but within a certain limit because you have to be at least able to justify that budget." This means that in the implementation of MA, tracking and measuring are considered key aspects.

On performance measurement, other specific factors justify the insurgence of accountability in the marketing field, namely the existence of new metrics to carry out this measurement in the right way. Manager 7 observed that "before SaaS became mainstream, we still kind of held onto the old vanity metrics (. . ), it feels like we were more tied to the agency metrics because they were the ones defining marketing at the time, whereas now, in every company I worked with, there is a very big grip on revenue." This reflects a shift toward perceiving marketing as responsible for the financial outcomes of a company by directly relating its measurement to value creation. Manager 6 added that "accountability has pushed the firm to understand better ways to use time and continuous learning on the basis of previous assessments. (...) Only this way the process is worth." This claim positions MA at both operational and strategic levels, giving it a value creation role.

Overall, the following aspects were found as the most significant among the decisive factors for this increasing demand for accountability: the ability to measure activity outcomes; the increased levels of competition; the existence of new and better metrics (directly related to financial outcomes of the firm); the arrival of new tools for performance measurement; the explosion of data and, finally, the need to justify the budget allocation.
Marketing
accountability
and
automation 
EMJB 18,1

These findings shed light on the need to create a value-based agenda grounded in resources specifically and strategically devoted to accountability, which ultimately support MA implementation.

\subsection{Reaching accountability}

Reaching marketing accountability, despite its usefulness, presents a considerable challenge to marketers. Each marketing manager witnesses increased pressure to work with large amounts of data, selecting the right metrics to measure, knowing when to measure them and prove their value to the company as a whole through the activities they undertake.

The ability to tie metrics to business outcomes emerged as fundamental for the interviewed managers. For example, manager 1 explained that "there's always need to try and connect metrics that are no't necessarily related to the business and tie them to business outcomes". And manager 6 observed: "Nowadays you can have Marketing campaigns that are super targeted, which you did no't have before. With these tools you can have super specific communication with a given segment, so you can communicate with people almost as if they were one, which brings you much closer to them, and allows to understand what they truly want, so you can adjust your offer accordingly." When inquired on which metrics were considered the most important for the current activities undertaken by a company's marketing team, manager 8 further corroborated the need to correlate metrics to business outcomes, thus corroborating that decisions should be data-driven: "With higher management, we work around ROI (Return on Investment), margins, and things that are important for the business. (...) Each business and each marketer need to define their own KPIs (Key Performance Indicators) and their metrics, not limiting themselves to two or three, but look at all the metrics that are related to the business." This reinforces the importance of selecting the right measures.

Also, in direct correlation with the need to tie marketing metrics to business outcomes is the need to establish a common language and maintain alignment within strategic and operational activities and ultimately company goals. As stated by manager 4, "there has to be a common language, common goals in order to demonstrate value and prove results. It is necessary that fluid and clear communication is established between both parties for marketers to make their superiors understand what activities they are undertaking, why, and how they ultimately relate to the company goals." As such, the outcome between the two levels seems to be very important and result in a win-win situation for marketing managers, who are now able to pull numbers that prove their value to the company, simultaneously justifying further budget allocation for their teams and their activities, while the top management team finds an outlet for the accountability that marketing departments require.

The new data-driven paradigm pushes marketers to develop new abilities and ponder the importance of implementing a data strategy inside their companies and their teams. Therefore, knowing what and when to measure become vital, as explained by manager 2: "We have plenty of data. Orchestrating all of that is very complicated, but sometimes we realize that data obtained from one of our strategic business units are also useful for others." This definitively justifies the use of MA for business scalability, which should, hence, be part of the value-based agenda. However, because businesses and markets are different from one another, tools and strategies implemented by marketing teams also differ. Therefore, reaching accountability in marketing does not rely on finding metrics with a universal fit, but rather on each company selecting the metrics that accurately depict the business environment in which they operate, their target audiences, their channels, their strategies, as well as the goals and objectives that are specific to each organization. This essentially requires testing processes through a sort of trial and error approach. This concept was further highlighted by manager 5, who indicated that "to know exactly what metrics you should 
look for is a huge challenge. (...) You have to put significant work into your KPI dashboard." The existence of a well-crafted metrics dashboard is also considered important for a marketer's performance measurement across a plethora of activities as explained by manager 7: "The metrics in our pipeline change very little. (...) If you keep changing your metrics, you cannot compare yesterday's reality with today's reality. If you cannot make that comparison, you cannot make decisions based on that and change your strategy." In parallel with the decision of what to measure is the decision of when to measure metrics, aiming at testing and reporting. On this point, for instance, manager 9 observed that "in marketing, it's very important to measure in real-time, and measure all the metrics, and have alerts, and base management decisions on results." So, ultimately, the CMO becomes an important person of the value creation process.

\subsection{Marketing automation implementation}

The use of MA software emerged as a relevant theme in our interviews and helped marketers track and pursue marketing accountability. Accordingly, automation occurs throughout the entire funnel, from lead acquisition to the conversion stages, with direct effects on the accountability of marketers, and it is mediated by strategic and operational marketing. For instance, manager 7 explained MA's usefulness as follows: "We automate a lot of things, we have dozens of automated workflows, that put a stage 2 client on stage 3, activate and deactivate leads, distribute leads by each market." Thus, MA seems to become a crucial factor in the success of activities undertaken by marketing teams and to sustain future decisions on the basis of the results of previous actions. This success stems mainly from the ability to strategically set up workflows that, once implemented, can easily be replicated and allow for the sustainable scalability of the business. Manager 6 further described the role of workflows and assistance of MA platforms for team regular adjustments: "We use it for the definition of workflows, from being a lead to becoming a subscriber, we use it on the email automation side, we use it for re-engagement. So, if an MQL (marketing qualified lead) kind of dies and is not answering phone calls, we kick it back to a workflow to try to get them re-engaged."

As with any new technology, tool or strategy, MA software brings its string of challenges in implementation, further intensified by its novelty. The two main challenges identified as patterns from the interviews rest mainly in the technical aspect of implementation and automation testing. The technical aspect invariably requires know-how that companies may not have or, if they do, demands that some level of resources are allocated to the successful implementation of the software. On this point, manager 1 explained: "The initial point is that you have to allocate resources - these are tools, and especially in the set-up process, for you to be able to prepare the tool in order for it to answer your needs, you will always have to allocate at least one person for that." Developing on the topic of technological complexity, manager 8 revealed that "it may be hard during the first stages, especially if you are no't a very technical person, it can become quite scary." This aspect is also related to another issue that emerged from interviewed marketers, namely the need to reinvent themselves by developing competencies that were not part of their role in the past, placing further emphasis on the CMO as a value creator within the firm. The second challenge relates to the issue of automating processes that have not been previously tested. The appropriate and successful implementation of MA implies that workflows and processes that are being automated are in tune with the needs and strategies of the team. On this matter, manager 4 stated that "with $M A$, it becomes really easy for you to think that you have a great process, just because it looks good on paper. First, you have to know that you have a good process and that the process works, and only then move on to the automation of that process through MA. Often, people do the opposite, getting it just because, and you spend a lot of time creating a process that ends up not 
EMJB 18,1

being scalable." Despite certain limitations of MA, there was consensus among interviewees regarding the benefits associated with its implementation. These benefits can be summarized in improvements in scalability, productivity and accountability. These aspects are recognized as the result of the work of CMOs as value creators, as it was acknowledged by manager 10 that said: "It is also our role to understand which processes require further investment and insistence in the next round, and which do not."

In terms of productivity, implementing one or more MA software ultimately leads to the ability to do more with less. As described by Manager 4, with MA "you can have a much bigger outcome with fewer people. Your team can now be on a superior level just because they are no't simple doers. They have to think about the process, measure the process, not just the manager, all team members, and they have to think about what they did, measure what they did, and constantly improve." The automation of tasks allows marketers to spend more time strategizing and developing other activities that ultimately bring more value to the firm also in terms of productivity (Cascio et al., 2010). Hence the organization of marketing activities through the implementation of MA allows the firm to deliver better results within the existing budget and potentially align or even exceed the pre-defined objectives.

Closely related to productivity is the benefit of scalability. Manager 5, for instance, explained the link between MA and scalability as follows: "We can scale easily. One person can write one workflow, and it can reach hundreds of people every single day, really easily", a statement further developed by Manager 10, who referred to MA as an asset allowing the business "ultimately, to (...) scale. The ability to collect thousands of leads and keeping them boiling for a long time. I think scalability is possible, and instead of doing something on a one-toone basis, we can do it in a one-to-many approach. Automation allows us to get that scale without much fear of destroying a population of a million potential customers". Additionally, referring to the possibility of better targeting through MA that eventually leads to a broader base of customers and, consequently, profitability and value, Manager 5 stated: "Automation allows us to develop campaigns on a much larger scale, that we would never be able to do manually, campaign though campaign. What happens is that it allows for bigger volume, where we can simultaneously act more granularly, by country, by city, anything, much faster and more granularly."

The last benefit is related to MA's impact on tracking and measuring the return on marketing activities inside the organization. For instance, manager 9 puts forward the notion of showcasing results and its direct effect on the personal side of the profession: "I feel like this type of optimization is so important for marketing professionals. This is something that actually means a lot to me because, personally, I do not enjoy working and not being able to prove what I'm doing matters. So, it's amazing!' In addition to the ability of marketing managers to prove themselves as value creators and justify further budget allocation through enhanced performance measurement, other issues described in this paper conclusively tie down with MA, namely data collection and analysis and the development and monitoring of metrics dashboard. Ultimately, the successful implementation of MA led marketers to become more accountable and this, more valued, as explained by manager 4: "With MA, you can no longer measure your work through output, but rather through outcome. Before you could say I worked so hard, I sent 150 emails today. Well, now, those 150 emails are sent automatically. You sent them, but what were the results."

\section{Discussion and conclusions}

Accountability in marketing seems to be no longer optional (Lamberti and Noci, 2010), as evidenced by the growing interest in marketing accountability in recent years (Stewart, 2009). Accordingly, one of the main challenges that marketers face is the accurate financial performance measurement of their activities (Copulsky et al., 2016). As such, our study 
outlines the benefit of MA implementation and sheds light on MA as a factor that can enable marketers to enhance the accountability of marketing activities.

The findings derived from the interviews allowed for the emergence of new patterns and singularities, culminating in a framework for marketing accountability presented in Figure 2. This framework, which is based on the findings of this research, summarizes the most important elements, as well as dynamics and synergies between them, for companies desiring to reach accountability in marketing. In particular, the framework proposes a model for marketing accountability that considers the role and potential impact of MA in firms. The implementation of MA, however, should not be regarded as the driving force of the activities carried out by the marketing team but rather as a powerful tool for productivity (Heimbach, 2015), scalability (Patterson, 2014) and accountability (Grossberg, 2016; Hanssens and Pawels, 2016).

The strategic marketing level in the framework corresponds to all the activities undertaken by the senior marketing team and the people responsible for the company's strategic planning. At this level, decisions are made on the basis of a selection of metrics assuming the need to report to higher management, namely the CEO. At the operational marketing level, and following a data strategy entailing testing of processes, it is crucial to select the right set of metrics for performance measurement and the successful implementation of MA, which involves the treatment of data for predictive analysis and data-driven decisions on campaigns, tracking and measuring, and regular adjustments. Both levels intend to create the foundation for a value-based marketing agenda that, with the assistance of MA, will ultimately result in sustainable long-term business growth, higher marketing return on investment (MROI), further budget allocation for future marketing endeavors and the establishment and perception of the CMO as a value creator for the company.

In order to reach accountability, we propose that marketing managers' focus should rest on the strategic marketing level, continuous improvement with MA and the operational marketing level in order to maintain an open and transparent relationship between the activities that are undertaken within the scope of the marketing team and the company as a whole. As such, each element should interact with each other so that the activities stemming from operations clearly work in parallel and under the influence of the elements resulting from the strategic marketing level, thus fully accounting for marketing as partly responsible for the ultimate business outcomes.

At the operational marketing level, the benefits of automated processes, and the capabilities of MA to set these processes in motion, should not be anticipated as a goal in itself; rather, automation should be perceived as a tool that ultimately leads the team to achieve the determined specific goals, and eventually lead to successful results for the firm (Järvinen and Taiminen, 2016). Before carrying out MA, it is important to outline processes that clearly describe the marketing strategy, which activities will be carried out within that strategy, and the ultimate expected outcomes. This entails a careful selection of metrics to measure pre-defined outcomes (Grossberg, 2016). These metrics will vary from firm to firm, as each business operates within its specific environment, market and target audience (Keens and Barker, 2009). However, these metrics must be in direct alignment with managerial business goals (Copulsky et al., 2016). Upon selecting metrics for the performance measurement of marketing activities, managers must be aware that these should ultimately be related to financial metrics to fully understand the depth in which the activities are contributing to company profit (O'Sullivan and Abela, 2007). Additionally, in the early stages of outlining and testing processes, metrics may change to recognize the assessment quality and exact validity of measurement. However, once a set of metrics is defined, it should not be the target of constant change. For instance, metrics should not be changed just because the obtained results are not as expected. The proposed measures should 
EMJB 18,1

be kept constant for a certain period so that marketers can have a solid basis for comparison. If changes in the metrics used occur frequently, accountability may not be achieved, and marketing strategy could not be accurately defined; learning from its use would not be obtained either.

Once the processes are outlined and before any implementation, it is relevant to assess the firm's capabilities and readiness for adoption and implementation (Järvinen and Taiminen, 2016; Vlačić et al., 2021). This validation method is key to avoid automating a process that the team is not sure about in terms of fit and replication. Avoiding this validation might result in the automation of errors, resulting in losses for the company. If the processes prove to be successful when tested, then teams can proceed to the stage of replication through the implementation of MA. The successful implementation of MA involves the adoption of datadriven decisions (Järvinen and Taiminen, 2016; Grandhi et al., 2020), tracking and measuring (Liang and Gao, 2020), and adjustment (Järvinen and Karjaluoto, 2014). Data-driven decisions are made according to the intelligence gathered from tracking and measuring of performance activity, which, in turn, allows for continuous adjustment of elements. These adjustments are once again measured against previous results, leading to further decisions based on this measurement, resulting in a continuous improvement of marketing performance. The tracking and measuring represented by tracking and adjustment stem from the previously defined metrics that are prone to be automated through dashboards and reports, providing a holistic view of all activity performance in real-time.

The elements at the operational marketing level ultimately relate to continuous learning and assessment of the CMO and top management (Slater and Narver, 1995; Sheth and Sisodia, 2002). While the top management should regularly assess the activities carried out by the marketing team, the marketing team should be concerned about continuously learning through this process and pick up on issues that may call for further knowledge and competencies to be acquired or for processes to be fine-tuned.

Combining the elements that compose the operational and strategic marketing levels with MA software enables an enhanced value-based marketing agenda that holds marketers accountable for their activities and seeks to deliver value to the firm. This should result in the perception of the CMO as a value creator through the ability to display results to the top management team in a way that expresses business outcomes, business scalability through the ability to continuously monitor performance, adjusting variables and making data-driven decisions. It also includes the possibility of doing and delivering more with the added advantage of maintaining the number of people on the team, and further budget allocation to the marketing department, by pulling numbers that justify the need for more financial resources (Sheth and Sisodia, 2002).

Despite MA's advantages for marketing accountability emerging from our interviews and summarized in the proposed framework, MA presents challenges that need to be addressed to fully unlock its potential. Overcoming such challenges is of paramount importance in light of the complexity and dynamism of the business environment. Building on this study's findings, we summarize below some of the potential obstacles that marketers may face when automating the marketing process and offer a critical reflection on how these might be overcome (see Table 3).

MA, as the perceptions of our interviewees illustrate, is still in the early stages of adoption, with many companies taking the first steps into learning the benefits and challenges associated with the automation of marketing tasks (Vrontis and Thrassou, 2013), and its role in measuring performance. A definitive answer to all these matters call for more profound and in-depth research on the subject (Arslanagic-Kalajdzic and Zabkar, 2015).

The present study is not without limitations. One limitation is related to the selection of the interviewees, which includes only professionals working for companies located in one country, therefore limiting the generalizability of our findings to other countries. Future 
Obstacle

Continuous evolution on the technology-side implies that new tools will be introduced in the market, requiring continuous improvements of previous MA software versions

Marketers should be wary of not automating in excess

There can also be resistance from marketing practitioners to embrace technology, mostly because this demands the development of new competencies that were not considered inherent to the field of marketing in the past

Although there are tools available for better collection, storage, and analysis of data, the amount of information marketers has access to will continue to expand. The definition of a data strategy provides a solid base to overcome this fact partly
Critical reflections

This entails that marketers will have to make decisions based on whether or not further investment in these tools is justified, not just in terms of financial but also in terms of human resources. MA implies that marketers get adjusted and proficient on a given technology, and constantly substituting those technologies in very short periods results in more time spent learning about the new software It is paramount that, when deciding to automate, marketing managers carefully research their options and stay faithful to their choice to not incur in taking away from one of the most fundamental benefits of MA in the first place - team productivity

The human factor is an element of marketing that cannot disappear, whether in a $\mathrm{B} 2 \mathrm{~B}$ or $\mathrm{B} 2 \mathrm{C}$ environment, since products and services are being exchanged between people. Losing the human factor can be a determinant cause for failure, and automation in excess may ultimately damage the company Failure to embrace the new tools available in favor of relying on instinct and experience alone might have negative repercussions on the overall performance of the companies and represent a barrier to achieving accountability. Marketers who do not embrace the new data and technology-driven paradigm may fail at becoming value-creators for their firm and may ultimately be replaced

This still poses a considerable challenge for practitioners and demands that ample effort is put into developing further analytical abilities in parallel with the aforementioned technological skills

\section{Marketing accountability and \\ automation}

159

Table 3.

MA and marketing accountability - a critical reflection

studies may explore the impact of MA on performance measurement in other settings (e.g. different countries, business to business (B2B) versus business to consumer (B2C) businesses), analyzing several data strategies inside companies, and how these relate to the success or failure of MA implementation. Another limitation is related to the reliance on key informants that are internal to the interviewed firms. While managers' views are widely recognized as a reliable source of information, firms are embedded in complex ecosystems whose actors affect marketing-related decisions. Therefore, future studies may explore the link between MA and marketing accountability by also taking into account the perspective of external actors such as customers or suppliers.

Research remains scarce in what concerns the best practices in terms of the implementation of software and digital tools developed to improve marketing teams' performance. In that respect, the role of technologies aimed at performance improvement requires more empirical research. This issue has become more relevant in light of the recent coronavirus disease 2019 (COVID-19) pandemic, which has generated an upsurge in online sales, increasing the availability of marketing data. In that respect, MA offers new opportunities to better inform decision-making and better evaluate the ROMIs. While this paper represents an attempt to address this novel and timely issue, more theoretical and empirical research is warranted. 

EMJB
18,1

\section{References}

Alsaad, A.K., Yousif, K.J. and AlJedaiah, M.N. (2018), "Collaboration: the key to gain value from IT in the supply chain”, EuroMed Journal of Business, Vol. 13 No. 2, pp. 214-235.

American Marketing Association (2005), Marketing Accountability Study: White Paper, American Marketing Association, Chicago, IL.

Arslanagic-Kalajdzic, M. and Zabkar, V. (2015), "The external effect of marketing accountability in business relationships: exploring the role of customer perceived value", Industrial Marketing Management, Vol. 46, pp. 83-97.

Biegel, B. (2009), "The current view and outlook for the future of MA", Journal of Direct, Data and Digital Marketing Practice, Vol. 10 No. 3, pp. 201-213.

Bornet, P., Barkin, I. and Wirtz, J. (2021), Intelligent Automation: Welcome to the World of Hyperautomation, World Scientific Publishing, Singapore.

Brinker, S. and McLellan, L. (2014), "The rise of the Chief marketing technologist", Harvard Business Review, Vol. 92 No. 7, pp. 82-85.

Bucklin, R., Lehmann, D. and Little, J. (1998), "From decision support to decision automation: a 2020 vision”, Marketing Letters, Vol. 9 No. 3, pp. 235-246.

Cascio, R., Mariadoss, B.J. and Mouri, N. (2010), "The impact of management commitment alignment on salespersons' adoption of sales force automation technologies: an empirical investigation", Industrial Marketing Management, Vol. 39 No. 7, pp. 1088-1096.

Copulsky, J., Bergstrom, A. and Simone, M. (2016), "One tweak at a time: how analytics improved our content marketing”, Applied Marketing Analytics, Vol. 2 No. 3, pp. 201-212.

Coursera (2019), "Global skills index", available at: https://pages.coursera-for-business.org/rs/748-MIV116/images/global-skills-index.pdf (accessed 08 September 2020).

Davenport, T.H. (2014), "How strategists use 'big data' to support internal business decisions, discovery and production", Strategy and Leadership, Vol. 42 No. 4, pp. 45-50.

Davenport, T.H. and Philips, J. (2016), “The future of MA", Applied Marketing Analytics, Vol. 2 No. 3, pp. 213-224.

Duarte, P. and Silva, S. (2020), "Need-for-touch and online purchase propensity: a comparative study of Portuguese and Chinese consumers", Journal of Retailing and Consumer Services, Vol. 55, pp. 102-122.

Dubois, A. and Gadde, L.-E. (2014), “Systematic combining'-a decade later”, Journal of Business Research, Vol. 67 No. 6, pp. 1277-1284.

Eisenhardt, K.M. (1989), "Building theories from case study research", Academy of Management Review, Vol. 14 No. 1, pp. 532-550.

Festa, G., Shams, S.R., Metallo, G. and Cuomo, M.T. (2020), "Enhancing stakeholder networks in wine tourism-evidence from Italian small municipalities", EuroMed Journal of Business, Vol. 15 No. 3, pp. 349-360.

Fletcher, M., Zhao, Y., Plakoyiannaki, E. and Buck, T. (2018), "Three pathways to case selection in international business: a twenty-year review, analysis and synthesis", International Business Review, Vol. 27 No. 4, pp. 755-766.

Gehman, J., Glaser, V.L., Eisenhardt, K.M., Gioia, D., Langley, A. and Corley, K.G. (2018), "Finding theory-method fit: a comparison of three qualitative approaches to theory building", Journal of Management Inquiry, Vol. 27 No. 3, pp. 284-300.

Gillon, K., Aral, S., Lin, C.Y., Mithas, S. and Zozulia, M. (2014), "Business analytics: radical shift or incremental change?", Communications of the Association for Information Systems, Vol. 34 No. 1, p. 13.

Gioia, D.A., Corley, K.G. and Hamilton, A.L. (2013), "Seeking qualitative rigour in inductive research: notes on the Gioia methodology", Organizational Research Methods, Vol. 16 No. 1, pp. 15-31. 
Grandhi, B., Patwa, N. and Saleem, K. (2020), "Data-driven marketing for growth and profitability", EuroMed Journal of Business, Vol. ahead-of-print No. ahead-of-print, doi: 10.1108/EMJB-092018-0054.

Grossberg, K.A. (2016), "The new marketing solutions that will drive strategy implementation", Strategy and Leadership, Vol. 44 No. 3, pp. 20-26.

Hajdas, M., Radomska, J. and Silva, S. (2020), “The omni-channel approach: a utopia for companies?”, Journal of Retailing and Consumer Services, p. 102131, doi: 10.1016/j.jretconser.2020.102131.

Hanssens, D.M. and Pauwels, H. (2016), "Demonstrating the value of marketing”, Journal of Marketing: AMA/MSI Special Issue, Vol. 80, pp. 173-190.

Heimbach, I. (2015), "Marketing automation", Business and Information Systems Engineering, Vol. 57 No. 2, pp. 129-133.

Huang, M.H. and Rust, R.T. (2021), "Engaged to a robot? The role of AI in service”, Journal of Service Research, Vol. 24 No. 1, pp. 30-41, doi: 10.1177/1094670520902266.

Järvinen, J. and Karjaluoto, H. (2014), "The use of web analytics for digital marketing performance measurement”, Industrial Marketing Management, Vol. 50, pp. 117-127.

Järvinen, J. and Taiminen, H. (2016), "Harnessing MA for B2B content marketing", Industrial Marketing Management, Vol. 54, pp. 164-175.

Joshi, A. and Giménez, E. (2014), "Decision-driven marketing”, Harvard Business Review, Vol. 92 No. 7, pp. 64-71.

Kauffman, R.J., Ma, D. and Yu, M. (2018), "A metrics suite of cloud computing adoption readiness", Electronic Markets, Vol. 28 No. 1, pp. 11-37.

Keens, D. and Barker, D. (2009), "MA systems integration: the art and engineering to make it all work seamlessly", Journal Direct, Data Digital Marketing Practice, Vol. 10, pp. 223-232.

Kübler, R.V., Wieringa, J.E. and Pauwels, K.H. (2017), "Machine learning and big data”, im Leeflang, P., Wieringa, J., Bijmolt, T. and Pauwels, K. (Eds), Advanced Methods for Modeling Markets, International Series in Quantitative Marketing, Springer, Cham, pp. 631-670.

Kumar, V. and Sharma, A. (2017), "Leveraging marketing analytics to improve firm performance: insights from implementation”, Applied Marketing Analytics, Vol. 3 No. 1, pp. 58-69, (12).

Kumar, V., Ramachandran, D. and Kumar, B. (2020), "Influence of new-age technologies on marketing: a research agenda", Journal of Business Research, Vol. 125, pp. 864-877.

Lamberti, L. and Noci, G. (2010), "Marketing strategy and marketing performance measurement system: exploring the relationship", European Management Journal, Vol. 28, pp. 139-152.

Liang, X. and Gao, Y. (2020), "Marketing performance measurement systems and firm performance", European Journal of Marketing, Vol. 54 No. 4, pp. 885-907.

Lois, P., Drogalas, G., Karagiorgos, A. and Tsikalakis, K. (2020), "Internal audits in the digital era: opportunities risks and challenges", EuroMed Journal of Business, Vol. 15 No. 2, pp. 205-215.

Makrides, A., Vrontis, D. and Christofi, M. (2020), "The gold rush of digital marketing: assessing prospects of building brand awareness overseas", Business Perspectives and Research, Vol. 8 No. 1, pp. 4-20.

Malshe, A., Friend, S.B., Al-Khatib, J., Al-Habib, M.I. and Al-Torkistani, H.M. (2017), "Strategic and operational alignment of sales-marketing interfaces: dual paths within an SME configuration", Industrial Marketing Management, Vol. 66, pp. 145-158.

Mero, J., Tarkiainen, A. and Tobon, J. (2020), "Effectual and causal reasoning in the adoption of MA", Industrial Marketing Management, Vol. 86, pp. 212-222.

Minichiello, V., Aroni, R. and Minichiello, V. (1990), In-depth Interviewing: Researching People, Longman Cheshire, Melbourne.

Mishra, S. (2011), "Current industry approaches towards marketing ROI: an empirical study", The European Journal of Business Management, Vol. 3 No. 6. 
EMJB 18,1

Morgan, N.A., Clark, B.H. and Gooner, R. (2002), "Marketing productivity, marketing audits, and systems for marketing performance assessment: integrating multiple perspectives", Journal of Business Research, Vol. 55 No. 5, pp. 363-375.

O'Sullivan, D. and Abela, A. (2007), "Marketing performance measurement ability and firm performance", Journal of Marketing, Vol. 71, pp. 79-93.

Patterson, L. (2014), "How best-in-class marketers use alignment and accountability for value creation", Applied Marketing Analytics, Vol. 1 No. 2, pp. 168-174.

Read, S., Dew, N., Sarasvathy, S.D., Song, M. and Wiltbank, R. (2009), "Marketing under uncertainty: the logic of an effectual approach", Journal of Marketing, Vol. 73 No. 3, pp. 1-18.

Redding, S. (2015), “Can MA be the glue that helps align sales and marketing?", Journal Direct, Data Digital Marketing Practice, Vol. 16, pp. 260-265, doi: 10.1057/dddmp.2015.27.

Santoro, G., Ferraris, A. and Winteler, D.J. (2019), "Open innovation practices and related internal dynamics: case studies of Italian ICT SMEs", EuroMed Journal of Business, Vol. 14 No. 1, pp. 47-61.

Sarmaniotis, C., Assimakopoulos, C. and Papaioannou, E. (2013), "Successful implementation of CRM in luxury hotels: determinants and measurements", EuroMed Journal of Business, Vol. 8 No. 2, pp. 134-153.

Sheth, J.N. and Sisodia, R.S. (2002), "Marketing productivity: issues and analysis", Journal of Business Research, Vol. 55 No. 5, pp. 349-362.

Siegel, E. (2016), Predictive analytics: the power to predict who will click, buy, lie, or die, Wiley, Hoboken, New Jersey, NJ.

Silva, S., Duarte, P. and Sundetova, A. (2020), "Multichannel versus Omnichannel: a price-segmented comparison from the fashion industry", International Journal of Retail and Distribution Management, Vol. 48 No. 4, pp. 417-430.

Silva, S., Rocha, T., De Cicco, R., Galhone, R. and Mattos, L. (2021), "Need for touch and haptic imagery: an investigation in online fashion shopping", Journal of Retailing and Consumer Services, Vol. 59, doi: 10.1016/j.jretconser.2020.102378.

Sinkovics, R.R. and Alfoldi, E.A. (2012), "Progressive focusing and trustworthiness in qualitative research", Management International Review, Vol. 52 No. 6, pp. 817-845.

Slater, S.F. and Narver, J.C. (1995), "Market orientation and the learning organization", Journal of Marketing, Vol. 59 No. 3, pp. 63-74.

Stanton, W.W. and Stanton, A.D. (2016), "The relationship between big data, data science, digital analytics and the skills and abilities needed to optimise marketing decisions", Applied Marketing Analytics, Vol. 2 No. 3, pp. 265-279 (15).

Stewart, D.W. (2009), "Marketing accountability: linking marketing actions to financial results", Journal of Business Research, Vol. 62, pp. 636-643.

Ulaga, W. (2003), "Capturing value creation in business relationships: a customer perspective", Industrial Marketing Management, Vol. 32 No. 8, pp. 677-693.

Vlačić, B., González-Loureiro, M. and Eduardsen, J. (2020), "The process of the process of internationalisation: cognitive and behavioural perspectives in small ventures", European Journal of International Management, Vol. ahead-of-print No. ahead-of-print, doi: 10.1504/EJIM. 2020.10027574 .

Vlačić, B., Corbo, L., Silva, S. and Dabic, M. (2021), “The evolving role of artificial intelligence in marketing: advanced topics and research agenda", Journal of Business Research, Vol. 128, pp. 187-203.

Vrontis, D. and Thrassou, A. (2013), Innovative Business Practices: Prevailing a Turbulent Era, Cambridge Scholar Publishing, Newcastle, GB.

Vrontis, D., Thrassou, A., Chebbi, H. and Yahiaoui, D. (2012), "Transcending innovativeness towards strategic reflexivity", Qualitative Market Research: An International Journal, Vol. 15 No. 4, pp. $420-437$. 
Vrontis, D., Bresciani, S. and Giacosa, E. (2016), "Tradition and innovation in Italian wine family businesses”, British Food Journal, Vol. 118 No. 8, pp. 1883-1897.

Vrontis, D., Thrassou, A. and Amirkhanpour, M. (2017), "B2C smart retailing: a consumer-focused value-based analysis of interactions and synergies", Technological Forecasting and Social Change, Vol. 124, pp. 271-282.

Wood, C. (2015), "Marketing automation: lessons learnt so far", Journal of Direct, Data and Digital Marketing Practice, Vol. 16 No. 4, pp. 251-254.

Wright, B., Fletcher, K., Donaldson, B. and Lee, J.-H. (2008), "Salesforce automation systems: an analysis of factors underpinning the sophistication of deployed systems in the UK financial services industry", Industrial Marketing Management, Vol. 37 No. 8, pp. 992-1004.

Yin, R.K. (2003), Case Study Research: Design and Methods, 3rd Ed., Sage Publications., Thousand Oaks.

\section{Further reading}

Aquino, J. (2013), "Streamlining your sales and marketing tasks with automated technology can do wonders for your productivity and your bottom line", Customer Relationship Management Magazine, Vol. 17, pp. 5-32.

Speier, C. and Venkatesh, V. (2002), "The hidden minefields in the adoption of sales force automation technologies", Journal of Marketing, Vol. 66 No. 3, pp. 98-111.

Srinivasan, S., Vanhuele, M. and Pauwels, K. (2010), "Mind-set metrics in market response models: an integrative approach", Journal of Marketing Research, Vol. 47 No. 4, pp. 672-684.

Tonkova, E. (2016), "Automated marketing and the need to revise traditional practices", Journal of Emerging Trends in Marketing and Management, Vol. 1 No. 1, pp. 167-174.

Wamba, S., Gunasekaran, A., Akter, S., Dubey, R. and Childe, S. (2017), "Big data analytics and firm performance: effects of dynamic capabilities", Journal of Business Research, No. 70, pp. 356-365.

\section{Appendix \\ Interview guide}

(1) The matter of accountability in marketing has been an issue for a long time, particularly in the past few years. Do you feel like your role as CMO demands more accountability than in the past? Why?

(2) What do you feel are the biggest challenges in reaching this accountability? How can they be overcome?

(3) How often do you measure the performance of your marketing activities? Do you feel you should do it more/less often?

(4) Do you have any set of metrics in place to measure the performance of your marketing activities? Do they change depending on internal/external factors?

(5) What do you think will change in the way CMOs measure their performance in the upcoming years?

(6) For which purposes are you currently using MA software?

(7) Do you feel like the implementation of MA has forced you to be more accountable? How?

(8) What are the biggest challenges that the implementation of MA has created with respect to the execution of your tasks?

(9) What are, in your opinion, the most positive outcomes of the successful implementation of MA? 

$\mathrm{EMJB}$
18,1

\section{About the authors}

Susana C. Silva is associate professor at Católica Porto Business School, Universidade Católica Portuguesa, where she is also a researcher at Research Centre in Management and Economics (CEGE). Susana is visiting professor at University of Saint Joseph, Macao/ China. She holds a PhD in Marketing from the University College de Dublin, Ireland. Her research interests include online retailing, digital consumer behavior, international marketing, internationalization process, social and cause-related marketing. She is the author of several books and book chapters published in Portugal, UK, China, USA and Brazil. Her main contributions are published in International Business Review, International Marketing Review, Journal of Business Review and Journal of Retailing and Consumer Services, among others journals. She is national representative of Portugal at European Marketing Academy and an active member of the European International Business Academy.

Leonardo Corbo is senior assistant professor of management at the University of Bologna. Prior to joining the University of Bologna, he was assistant professor of management at Católica Porto Business School. He holds a PhD in Business Administration from the University of Bologna and has worked as a Postdoctoral Research Fellow at LUISS University. He has been a visiting scholar at the Kellogg School of Management and the Sauder School of Business. His work has appeared in several peer-reviewed international journals including the Journal of Business Research, Organization Studies and Management Decision. Leonardo Corbo is the corresponding author and can be contacted at: leonardo.corbo@unibo.it

Božidar Vlačić is Assistant Professor at Católica Porto Business School and Distinguished Researcher at Research Centre in Management and Economics (CEGE), Universidade Católica Portuguesa (Portugal). Since 2018, he holds an International $\mathrm{PhD}$ with honors in Economic Analysis and Business Strategy from the University of Vigo, the University of Santiago and the University of A Coruña (Spain). His main contributions are published in journals such as J. of Business Research, Technovation, IEEE Transactions on Engineering Management, J. of Intellectual Capital and European J. of Int. Management. He is an active member of the European International Business Academy and chair of EIBA Early Career Network.

Mariana Fernandes holds an MSc in marketing from Universidade Católica Portuguesa and a bachelor's degree in communication sciences. She has been working as a content manager and a copywriter. Her interests include communication management, e-content marketing and digital communication.

For instructions on how to order reprints of this article, please visit our website:

www.emeraldgrouppublishing.com/licensing/reprints.htm

Or contact us for further details: permissions@emeraldinsight.com 